\title{
A IMPORTÂNCIA DE AULAS TEÓRICA E DE CAMPo PARA ABORDAR QUESTÕes AMBIENTAIS DO BIOMA CERRADO: UM ESTUDO DE CASO
}

\author{
THE IMPORTANCE OF THEORETICAL AND FIELD CLASSES TO ADDRESS \\ ENVIRONMENTAL ISSUES OF THE BRAZILIAN SAVANNA: A CASE STUDY
}

DOI: $10.23926 / R P D .2526-2149.2020 . v 5 . n 2 . p 1124-1138 . i d 745$

\section{Paulo Henrique \\ Mariano de Deus \\ Licenciado em Biologia (IFB) \\ Professor da Secretaria de \\ Estado de Educação do \\ Distrito Federal (SEEDF) \\ pauloah2011@gmail.com}

\section{Francisco Roque}

Doutor em Biologia Animal

(UnB)

Professor do Instituto

Federal de Brasília, Campus

Recanto das Emas (IFB)

francisco.roque@ifb.edu.br
Resumo: Devido aos problemas ambientais enfrentados pelo bioma Cerrado é urgente aplicar ações voltadas à sua proteção. Nesse sentido, a educação ambiental se mostra como uma excelente abordagem para a conscientização dos efeitos das ações humanas nesse bioma. Neste trabalho, realizado em março de 2018 no Instituto Federal de Brasília (Campus Recanto das Emas), foi avaliada a eficácia de aulas teórica e de campo para abordar os problemas ambientais observados nesse bioma. Nossos resultados sugerem que ambas as aulas foram satisfatórias. Isso porque em ambos os casos houve rendimento similar e aumento do interesse dos discentes pela questão ambiental. Portanto, os dados deste estudo sugerem que reflexões e ações discentes sobre questões ambientais independem da estratégia didática adotada.

Palavras-chave: Destruição ambiental. Estratégias didáticas. Proteção ambiental.

\begin{abstract}
Due to the great environmental problems faced by the Brazilian savanna it is urgent to implement actions aimed at its protection. In this sense, environmental education is an excellent approach for awareness the effects of human actions in this biome. In this work, carried out on March 2018 at the Federal Institute of Brasilia (Campus Recanto das Emas), we evaluated the effectiveness of theoretical and field classes to address the environmental problems observed in this biome. Our results suggest that both classes were satisfactory. This is because in both cases there was similar performance and an increase in the student's interest in the environmental issue. Therefore, the data of this study suggest that student reflections and actions on environmental issues are independent of the didactic strategy adopted.
\end{abstract}

Keywords: Environmental destruction. Didactic strategies. Environmental protection. 


\section{INTRODUÇÃO}

A atual intensificação da degradação ambiental é resultado do contínuo estabelecimento e desenvolvimento das sociedades humanas ao longo da Terra (NASCIMENTO; ARAÚJO, 2009). O Cerrado é um exemplo de savana tropical biodiversa que tem sido extensivamente transformado pelos humanos, por isso trata-se de um hostpot mundial de biodiversidade e também um sistema apropriado para estudar a temática degradação ambiental (KLINK; MACHADO, 2005; MITTERMEIER et al., 2011). Depois da Mata Atlântica, o Cerrado é o bioma brasileiro que mais perdeu área para a expansão de atividades humanas. Estimativas produzidas na década passada já mostravam que pelo menos $50 \%$ dos dois milhões de $\mathrm{km}^{2}$ originais do Cerrado já haviam sido perdidos e que, naquele ritmo de destruição, em 2030 esse bioma desapareceria (MACHADO et al., 2004). A agricultura e a pecuária foram as principais atividades antrópicas responsáveis por essas perdas, sendo que a pecuária sozinha promoveu a eliminação de cerca de $42 \%$ da área original do Cerrado. Esse processo de expansão agropecuária no Cerrado tem causado perdas da biodiversidade (KLINK; MACHADO, 2005), invasão por espécies exóticas (ALMEIDA-NETO et al., 2010), erosão dos solos (BONO et al., 1996), poluição de aquíferos (SOARES; PORTO, 2007) e alterações no regime de queimadas (RATTER et al., 1997). Dessa forma, a riqueza ambiental da savana mais biodiversa do planeta se encontra extremamente ameaçada, corroborando a necessidade de ações locais voltadas à conscientização do público em geral sobre as consequências desses problemas ambientais.

A educação ambiental (EA) tem se mostrado uma abordagem potencial para conscientizar o público em geral sobre os efeitos da degradação do ambiente. A EA tem por objetivo apresentar todos os aspectos da vida e ensinar como preservar o meio ambiente garantindo a sustentabilidade. Dessa forma, a EA promove o desenvolvimento do raciocínio crítico sobre questões socioambientais que pode resultar em mudanças de ações e atitudes no meio em que vivemos (HIGUCHI; AZEVEDO, 2004; JACOBI, 2004; ROCHA, 2010). Por isso, ela tem ganhado espaço.

Como ressalta Marcatto (2002, p.8), é "graças ao aumento do interesse pelas questões ambientais e aos recentes avanços tecnológicos e científicos que se conhece mais sobre os problemas ambientais do que se conhecia no passado". Ainda segundo Marcatto (2002), nas últimas décadas temos presenciado um crescimento significativo dos movimentos ambientalistas que resultaram em uma população mundial mais consciente dos impactos da degradação do meio ambiente sobre a qualidade de vida na Terra. Ainda assim, os avanços não 
têm sido suficientes para impedir a progressão acelerada dos processos de degradação ambiental.

Nesse contexto, a escola é uma das instituições sociais que pode contribuir para evitar ou minimizar os danos ambientais causados pelas ações humanas. Além de transmitir, reformular e construir conhecimento, essa instituição também é responsável por promover relações de cidadania, por exemplo, entre os indivíduos e o meio em que vivem (SANTOS; ROYER, 2020). Embora o principal objetivo da EA seja buscar a transformação da sociedade a partir da conscientização e mudança de comportamento, a escola constitui um ponto de partida importante porque trata-se de um local apropriado para formar indivíduos reflexivos sobre as questões socioambientais, os quais podem promover mudanças nas comunidades em que estão inseridos (GUIMARÃES, 2000).

Porém um dos grandes desafios dos docentes para alcançar as metas da EA é a escolha de qual estratégia didática promove uma educação voltada para o meio ambiente que implica em uma profunda mudança de valores. Para Zacarias (2000), a EA contribuirá para a formação de cidadãos conscientes e atuantes na realidade socioambiental local e global caso o senso crítico do seu público seja estimulado.

Nessa mesma linha de pensamento, Marcatto (2002, p. 4) afirma que

A EA deve sempre trabalhar o lado racional e estruturado juntamente com o sensível e de valores, a fim de propiciar oportunidades mais significativas que possam ampliar o interesse, a autoconfiança, o engajamento e a participação de indivíduos em promover benefícios socioambientais.

Marcatto (2002) ainda afirma que um dos meios é aprender fazendo porque isso favorece a compreensão das teorias. Sem a prática, ricas ideias podem permanecer para sempre no campo do imaginário ou acabar se perdendo. Como afirma Rodrigues et al. (2017), abordar a "EA" apenas com aulas expositivas ilustradas com slides não desperta um interesse ou um entusiasmo na maioria dos alunos para a preservação ambiental. Nesse sentido, os professores devem produzir ideias inovadoras que desenvolvam nos seus alunos a consciência e também assegurem a preservação ambiental.

Para Viveiro \& Diniz (2009), uma alternativa promissora para o ensino de EA são as aulas de campo porque colocam os educandos em contato direto com a natureza, o que favorece a sensibilização acerca dos problemas ambientais. Fernandes (2007, p. 22) define atividade de campo como "toda aquela que envolve o deslocamento dos alunos para um ambiente alheio aos espaços de estudo contidos na escola". Viveiro \& Diniz (2009) mencionam que as atividades de campo em Ciências podem ocorrer em diversos lugares, inclusive em áreas de preservação. 
Nesse caso, a ideia é usar uma estratégia de ensino na qual se substitui a sala de aula por outro ambiente, sendo natural ou não, porém um ambiente que forneça condições seguras para explorar as relações entre os seres vivos ali presentes e o homem.

Viveiro \& Diniz (2009, p. 2) também afirmam que

\begin{abstract}
quando se pensa em um ensino de qualidade, sobretudo em Ciências, é indispensável um planejamento que articule trabalhos de campo com as atividades desenvolvidas em classe. As atividades de campo permitem a exploração de conteúdos conceituais, procedimentais e atitudinais, o que possibilita que sejam também de grande valia em programas de EA.
\end{abstract}

Para vários autores (MOTOKANE; TRIVELATO, 1999; SENICIATO; CAVASSAN, 2004; FRENEDOZO et al., 2007; ANSELMO et al., 2013; FERREIRA; PASA, 2015; SANTOS; ROYER, 2020), as aulas de campo também são apontadas como uma metodologia eficaz. Isso porque elas podem estimular a participação dos alunos, melhorar o aproveitamento, permitir a exploração de conceitos abstratos e complementar assuntos já discutidos ou incentivar estudos posteriores. Para Carvalho (1998), para que um indivíduo compreenda o meio em que está inserido e onde exerce ações transformadoras é preciso participar de forma ativa perguntando, buscando os diferentes pontos de vista, formulando respostas, hipóteses, ou seja, significa agir como um observador que sabe 'ler' as relações naturais e sociais que constituem os fatos ambientais. Sabendo-se que as pessoas normalmente cuidam e preservam aquilo que conhecem (ANSELMO et al., 2013), a EA aliada às aulas de campo constitui uma estratégia de ensino potencial para a conscientização das atuais e futuras gerações sobre preservação ambiental.

Considerando que o universo estudantil é complexo, identificar os processos motivadores que levam os alunos a participarem de atividades de aprendizagem é um importante passo para usá-los apropriadamente em programas educacionais voltados para conscientizá-los sobre e torná-los protagonista na questão ambiental. Portanto, esta pesquisa teve como objetivo geral avaliar estratégias didáticas para ensinar os problemas ambientais observados no Cerrado, seus efeitos na vida dos seres humanos, a importância da preservação ambiental e o papel de cada um nesse processo. Especificamente, esta proposta teve como objetivo solucionar o seguinte problema: as aulas de biologia realizadas em campo despertam nos estudantes um maior interesse pela preservação ambiental e proporcionam um aprendizado mais envolvente e significativo do que aulas expositivo-dialogadas ilustradas com slides? Para auxiliar na resolução desse problema, foi formulada e testada a seguinte hipótese: o rendimento 
discente sobre as questões ambientais aumenta após a aplicação de ambas as aulas, porém é maior quando os alunos são submetidos a aula realizada em ambientes do Cerrado.

\section{Metodologia}

Esta pesquisa foi realizada em março de 2018 no Instituto Federal de Educação, Ciência e Tecnologia de Brasília (Campus Recanto das Emas - CREM) (Figura 1, feita no QGIS 3.0QGIS Development Team, 2020). Essa unidade, situada a aproximadamente $30 \mathrm{~km}$ a sudoeste de Brasília, ocupa um terreno de 25 hectares na transição entre as áreas rural e urbana do Recanto das Emas, Distrito Federal. Dessa forma, ao mesmo tempo em que se está na cidade, a comunidade acadêmica estuda e trabalha próximo a uma área verde extensa composta por chácaras e remanescentes de Cerrado. Além disso, é comum o descarte irregular de variados tipos de resíduos domésticos nas adjacências desse Campus. Devido às características descritas anteriormente, foi possível a aplicação e comparação de aulas teórica e de campo em ambientes naturais e degradados.

Figura 1 - Localização da área de estudo indicando o Instituto Federal de Brasília-Campus Recanto das Emas (IFB-CREM) e os pontos da trilha ecológica (círculos laranjas) onde foram realizadas atividades de campo com alunos dessa instituição. Dados produzidos no Quantum GIS

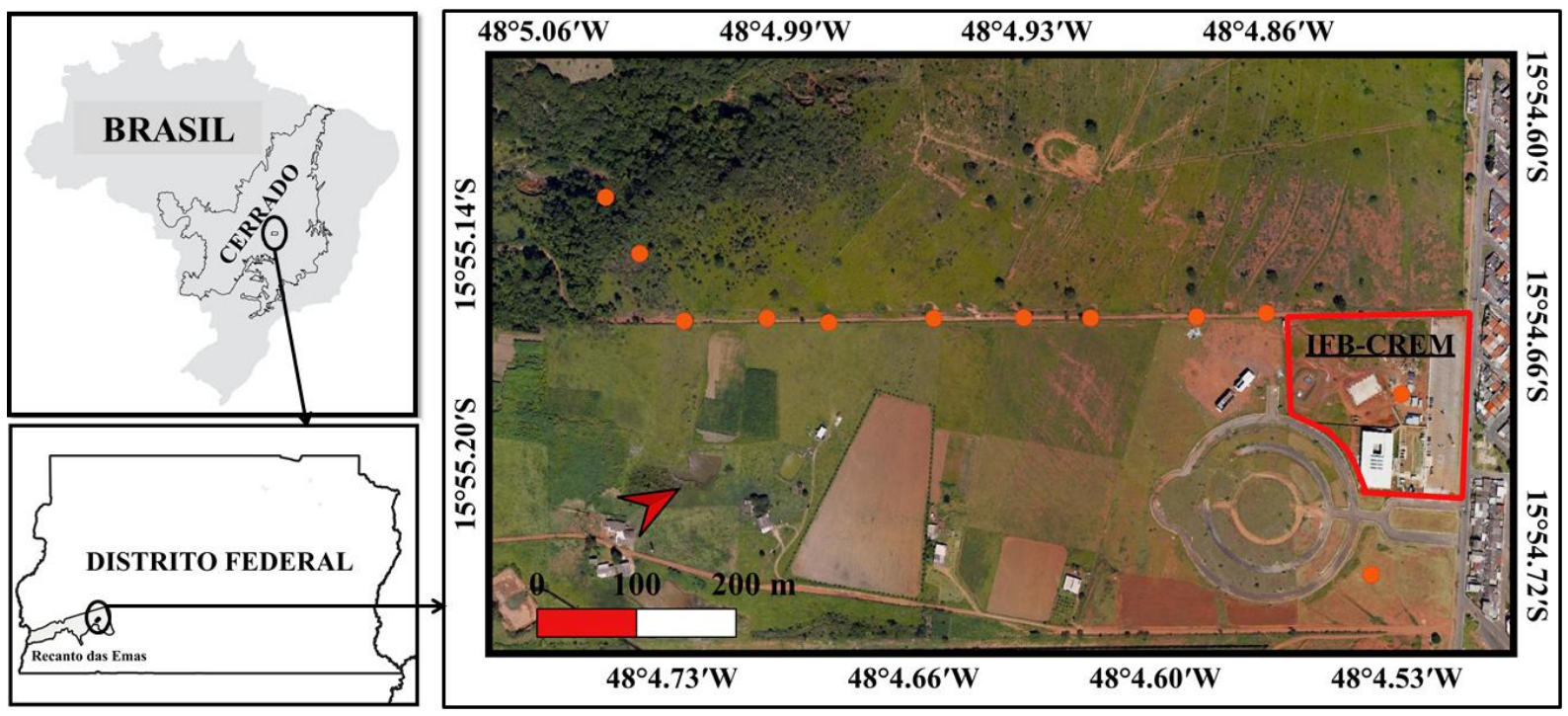

Fonte: Autores.

A participação nesta pesquisa foi condicionada ao preenchimento e assinatura de um Termo de Consentimento Livre e Esclarecido. Cada participante recebeu uma cópia desse termo. Dessa forma, todas as atividades realizadas neste estudo foram fotografadas e as imagens resultantes foram usadas para uma avaliação qualitativa das atividades desenvolvidas.

Participaram desta pesquisa 52 alunos de duas turmas do primeiro ano do curso técnico em audiovisual integrado ao ensino médio do CREM. Para um grupo de 26 alunos, foi aplicada 
uma aula teórica (expositivo-dialogada). Essa aula ocorreu em sala de aula convencional e consistiu na explanação e discussão dos principais problemas ambientais observados no Cerrado.

Para os outros 26 alunos, foi aplicada uma aula de campo ao longo de uma trilha ecológica pré-definida nas imediações do CREM. Ao longo dessa trilha, a qual consistiu de ambientes do bioma Cerrado degradados, preservados e em restauração, foram identificados os principais problemas ambientais e suas possíveis consequências para a natureza e a população humana local. Dentre os problemas ambientais observados e ensinados nessa trilha, podemos citar o, desmatamento, gramíneas exóticas, solo erodido e descarte de vários tipos de resíduos domésticos. Além de observarem fitofisionomias de cerrado sensu lato e matas de galeria relativamente preservadas ao longo dessa trilha, os alunos tiveram a oportunidade de conhecer a reserva legal do CREM que está em processo de implantação. Além disso, foi feita uma ecofaxina, ou seja, esse grupo foi dividido em equipes responsáveis pela coleta de tipos específicos de resíduos (plástico, vidro, papel e metal) encontrados ao longo da trilha. Ao final da trilha, os alunos descartaram os resíduos coletados em locais destinados à sua coleta pelo serviço público. Após o descarte, os alunos foram oralmente questionados sobre os efeitos causados pelos diferentes tipos de resíduos e também sobre o melhor procedimento a ser adotado. O objetivo dessa prática foi aplicar uma ação de conscientização nos alunos quanto a sua responsabilidade na preservação ambiental. Tais ações estão de acordo com as ideias de Nogueira et al. (2011), os quais argumentam que o desenvolvimento de atividades voltadas para questões ambientais pode sensibilizar e orientar os alunos para a preservação da natureza.

Para testar a hipótese deste estudo, no final de cada aula foram coletados dados quantitativos através de um questionário padronizado contendo questões sobre degradação e preservação do bioma Cerrado (Quadro 1). Por fim, esses dados foram convertidos em tabelas e gráficos para uma análise geral do rendimento dos estudantes submetidos aos dois tipos de aulas aqui avaliadas. Diferenças estatísticas no parâmetro rendimento foram medidas mediante a estatística não paramétrica Mann-Whitney (U), visto que os dados não apresentaram distribuição normal (Teoria (Shapiro-Wilk) $=0.79, p<0.001$; Campo $($ Shapiro-Wilk $)=0.88$, $p<0.05$ ). As análises foram feitas no programa PAST 3.18 (HAMMER et al., 2001). 
Quadro 1 - Questionário aplicado a alunos submetidos à aula teórica e de campo sobre questões ambientais do Cerrado

OBSERVAC̄̃̃ : As questões consideradas corretas estão destacadas em vermelho.

01. Qual bioma brasileiro localiza-se principalmente no centro do país?
a) Pampas.
b) Caatinga.
c) Cerrado.
d) Amazônia.
e) Pantanal.

02. Das opções abaixo, qual delas NÃO representa um problema ambiental observado no Cerrado.
a) Loteamentos irregulares.
b) Perda de biodiversidade.
c) Assoreamento dos rios.
d) Coleta seletiva.
e) Queimadas ilegais.

03. A conversão de uma área nativa em uma área urbana (cidade) pode acarretar inúmeros problemas ambientais, por exemplo:

a) Aumento da área verde.

b) Proteção dos recursos hídricos.

c) Aumento da permeabilidade do solo.

d) Diminuição da temperatura.

e) Inundação durante períodos chuvosos.

04. Quanto ao lixo urbano, qual das opções abaixo compreende um procedimento inadequado?

a) Tratar em estabelecimentos específicos.

b) Descartar diretamente nas ruas.

c) Reciclar.

d) Descartar em aterros sanitários.

e) Compostagem (produção de adubo) a partir da parcela orgânica do lixo.

05. Qual produto NÃO é um poluente dos rios?

a) Agrotóxicos.

b) Esgotos residenciais e industriais.

c) Óleos diversos.

d) Plásticos diversos.

e) Produtos biodegradáveis.

06. O processo de desertificação NÃO pode ser causado por:

a) Secas.

b) Queimadas.
c) Atividades agrícolas.
d) Desmatamento.
e) Reflorestamento de áreas degradadas.

07. Invasões biológicas consistem no transporte de espécies desde a sua região de origem até uma outra onde não ocorria, sempre através da ação humana. Como exemplo de espécie invasora, citase o caramujo africano no Brasil. São consequências causadas por essa espécie as listadas abaixo, exceto:

a) Disseminação de parasitoses.

b) Perda de espécies nativas.

c) Prejuízo econômico.

d) Equilíbrio ecológico.

e) Implicação sanitária à saúde humana.

08. Assinale a alternativa que NÃO apresenta uma solução para os problemas ambientais do bioma Cerrado.

a) Aumento das áreas destinadas à pecuária.

b) Incentivo às atividades sustentáveis.

c) Aumento das áreas de proteção do Cerrado.

d) Combate às queimadas ilegais.

e) Reflorestamento de áreas degradadas.

09. A preservação do Cerrado traz inúmeros benefícios para a natureza e a sociedade local, EXCETO:

a) Fornecimento de água potável.

b) Manutenção de nascentes.

c) Produção de alimentos.

d) Preservação da fauna e da flora nativas.

e) Poluição dos rios.

10. Como podemos conscientizar a população residente no bioma Cerrado sobre os problemas ambientais decorrentes da sua degradação?

a) Ampliando o ensino da educação ambiental nas escolas.

b) Realizando campanhas de divulgação nos diferentes veículos de comunicação sobre tais problemas.

c) Incentivando a participação de toda a sociedade na recuperação de áreas degradadas.

d) Denunciando para as autoridades competentes os crimes ambientais e seus autores.

e) Todas as alternativas anteriores estão corretas.

Fonte: Autores.

\section{Resultados e Discussão}

No geral, todos os 52 alunos pesquisados mostraram interesse durante as aulas fazendo vários questionamentos sobre a temática desta pesquisa (Figura 2). Vale a pena mencionar que 
em termos comparativos os discentes submetidos à aula teórica mostraram mais interesse pela atividade, sempre realizando discussões pertinentes. É importante ressaltar que essa aula foi aplicada em um ambiente mais limitado (sala de aula), onde os alunos estão mais próximos do professor responsável e que favorece o debate de ideias. Com relação aos rendimentos finais, as notas variaram entre 2,0 e 10,0 no grupo submetido a aula teórica e entre 3,0 e 10,0 no grupo tratado com aula de campo (Figura 3). A média das notas obtidas nessas duas abordagens didáticas foi praticamente similar (Figura 4) e, além disso, não houve diferenças estatísticas entre o rendimento dos dois grupos (U: $287 ; p=0.3$ ). No contexto deste estudo, esses dados não sustentam a hipótese de que apenas aulas de campos são estratégias didáticas eficientes para conscientizar estudantes sobre questões ambientais.

$\mathrm{Na}$ literatura, as aulas de campo são consideradas excelentes estratégias didáticas para o ensino de educação ambiental (EA) (MOTOKANE; TRIVELATO, 1999; SENICIATO; CAVASSAN, 2004; FRENEDOZO et al., 2007; VIVEIRO; DINIZ, 2009; ANSELMO et al., 2013; FERREIRA; PASA, 2015; SANTOS; ROYER, 2020). Esses autores argumentam que elas podem estimular a participação dos alunos, melhorar o aproveitamento e permitir a exploração de conceitos abstratos, além de complementar assuntos já discutidos ou incentivar estudos posteriores. A ecofaxina realizada neste estudo e os resultados que essa ação produziu seguem as previsões dos estudos anteriores e as evidências empíricas produzidas por Alves et al. (2018). Esses autores mostraram que a trilha ecológica usada como estratégia didática aprimorou o aprendizado discente sobre temas ambientais. Em termos de observação, os alunos avaliados neste estudo a partir da aula de campo também demonstraram muita curiosidade pela temática realizando vários questionamentos e demonstrando também grande disposição para realizar as atividades propostas. Além disso, durante a prática da ecofaxina foi notável a interação dos alunos uns com os outros. Como consequência, eles coletaram e descartaram em local apropriado diversos resíduos encontrados durante a trilha ecológica percorrida neste estudo. Tal ação permitiu conscientizar os participantes sobre as consequências do descarte incorreto de resíduos domésticos e está de acordo com os pressupostos de Nogueira et al. (2011) que argumentam que o desenvolvimento dessas ações pode sensibilizar e orientar os alunos para a preservação da natureza. 
Figura 2 - Visão geral dos grupos de alunos submetidos à aula teórica (A-B) e de campo (C-F) sobre degradação e preservação do Cerrado. Imagens produzidas em abril de 2018, no Instituto Federal de Brasília (Campus Recanto das Emas)
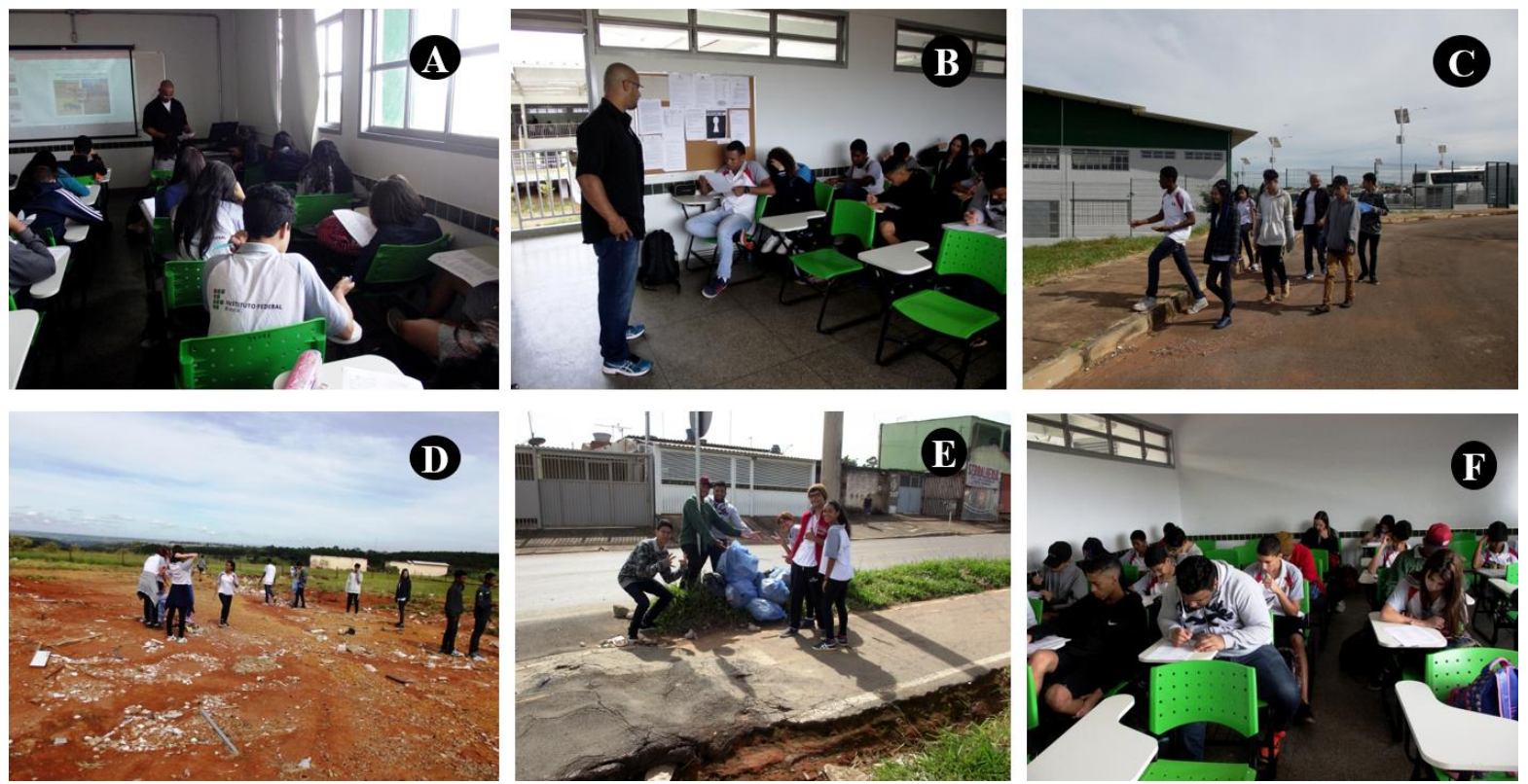

Fonte: Autores.

Embora considerada uma estratégia ultrapassada, a aula expositiva-dialogada avaliada neste estudo mostrou-se tão eficaz quanto à aula de campo para conscientizar os alunos pesquisados sobre as questões ambientais do Cerrado. Na literatura há resultados concordantes com os desta pesquisa (BRIGHENTI et al., 2015; MADEIRA, 2015). Brighenti et al. (2015) mostraram que essas aulas ainda são utilizadas pela maioria dos docentes e geralmente produzindo resultados significativos no aprendizado discente. Para Madeira (2015), os efeitos positivos de tais aulas podem decorrer da forma como os docentes as executam: o entusiasmo, alegria, disposição, criatividade e inovação são fatores que influenciam e podem melhorar a eficácia desse tipo de aula. As aulas expositivo-dialogadas, estratégia didática antiga e ainda muito utilizada, constituem, portanto, ferramentas didáticas que quando planejadas e executadas adequadamente podem potencializar o ensino de EA. 
Figura 3 - Notas obtidas por estudantes submetidos a uma aula teórica (barras pretas) e a uma de campo (barras cinzas) sobre degradação e preservação do bioma Cerrado. Dados coletados em abril de 2018, no Instituto Federal de Brasília (Campus Recanto das Emas)

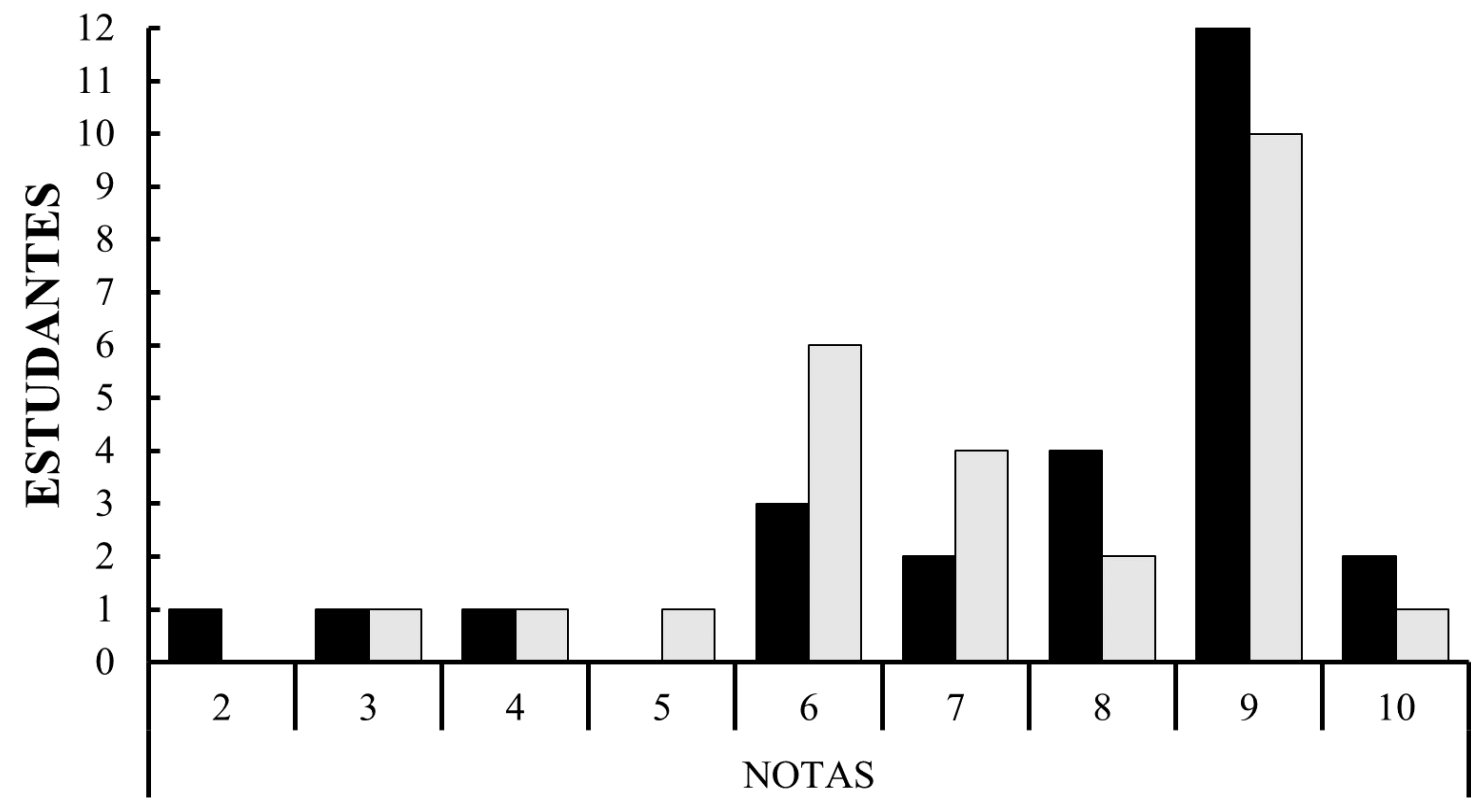

Fonte: Autores.

Figura 4 - - Médias e erros padrões (EP) das notas obtidas por alunos submetidos à aula teórica e de campo sobre degradação e preservação do bioma Cerrado. Dados coletados em abril de 2018, no Instituto Federal de Brasília (Campus Recanto das Emas)

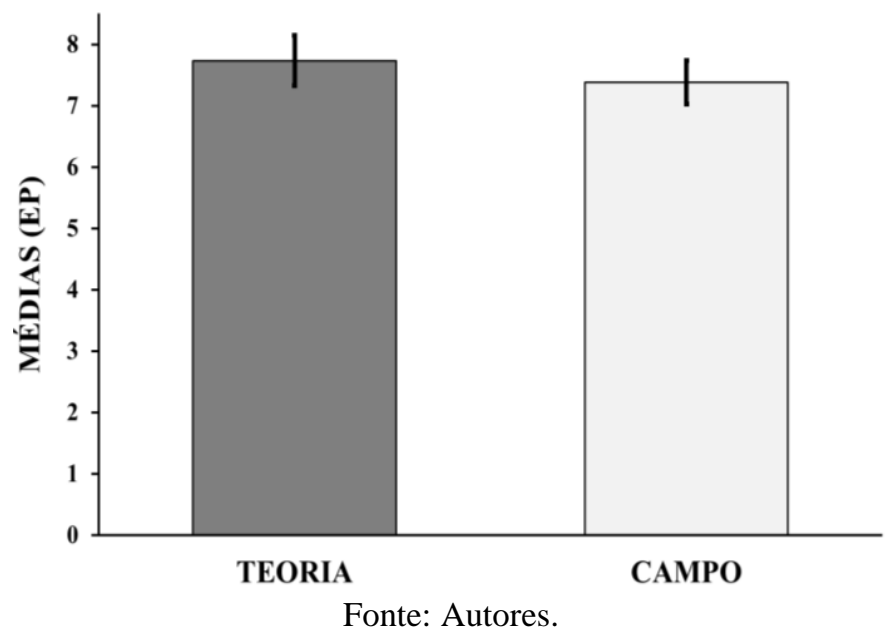

Para outros autores, se aliadas a aulas práticas e a resolução de exercícios, as aulas teóricas podem se tornar ferramentas mais poderosas no ensino e aprendizagem. $\mathrm{O}$ uso de diferentes modalidades didáticas na prática docente atende de forma mais ampla as diferenças individuais, além de contribuir para despertar o interesse discente pelos temas focais. Moraes et al. (2016), por exemplo, comparou uma turma submetida apenas a aulas teóricas com outra submetida a aulas teóricas associadas a aulas experimentais e verificou o notável desempenho daquela avaliada pela associação das duas metodologias. De qualquer forma e apesar das dificuldades temporais, logísticas, etc., enfrentadas pela maioria das escolas e professores 
brasileiros, é de extrema importância ir além do convencional para que um aprendizado mais significativo em EA seja obtido pelos estudantes e seja assegurada uma maior conscientização das atuais e futuras gerações sobre as questões ambientais.

Embora esta pesquisa tenha se limitado a avaliar a importância de dois tipos de estratégias de ensino para conscientizar o público focal sobre as questões ambientais do Cerrado, consideramos que parte dos objetivos da EA foram satisfeitos. Isso porque tratamos de questões ambientais reais nas duas aulas e em termos comparativos os dois grupos de estudantes avaliados neste estudo mostraram entusiasmo e crítica pela temática focal. Assim, esta proposta atende aos pressupostos de Dias (1991), o qual sugere que ensino de EA precisa vincular os processos educativos com a realidade, isto é, as atividades didáticas devem ser estruturadas em torno de problemas concretos impostos a determinada comunidade. Portanto, é possível que a aplicação das estratégias didáticas aqui avaliadas tenha desenvolvido habilidades intelectuais transformadoras das ações e atitudes no meio em que os pesquisados vivem. Por esta pesquisa ter limitação temporal, infelizmente estudos adicionais terão de ser feitos para constatar os efeitos práticos de tais intervenções. Por fim, por se tratar de uma temática bastante popularizada, recomenda-se também que estudos futuros avaliem o conhecimento discente antes e depois das intervenções didáticas realizadas para descartar eventuais ruídos nos resultados produzidos por eventual conhecimento já adquirido pelos discentes.

\section{CONSIDERAÇÕES FINAIS}

As práticas educativas relacionadas à questão ambiental podem assumir função transformadora, pois favorecem a conversão de indivíduos conscientizados em agentes promotores do desenvolvimento sustentável (DICKMANN; CARNEIRO, 2012). No contexto deste estudo de caso, podemos concluir que ambas as aulas expositivo-dialogada e de campo realizadas com estudantes do CREM foram satisfatórias e também contribuíram para a transformação dos alunos pesquisados. Isso porque nos dois casos os resultados obtidos indicaram rendimento similar e aumento do interesse dos alunos pela questão ambiental. Dessa forma, o presente estudo contribuiu para a construção de uma sociedade sustentável ao aplicar e testar diferentes estratégias didáticas que permitiram aos discentes refletir sobre os impactos e soluções advindas das relações desastrosas dos seres humanos com o meio ambiente.

\section{REFERÊNCIAS}


ALMEIDA-NETO, Mário; PRADO, Paulo I; KUBOTA, Umberto; BARIANI, Joice M.; AGUIRRE, Guilherme H.; Lewinsohn, Thomas M. Invasive grasses and native Asteraceae in The Brazilian Cerrado. Plant Ecology, v. 209, p. 109-122, 2010. doi: 10.1007/s11258-0109727-8.

ALVES, Edson Ferreira; OLIVEIRA, Itaní Sampaio; ALVES, Claúdio Nahum. Trilha ecológica pedagógica: um caminho para o ensino da educação ambiental em uma escola pública do município de Manaus (AM). Revista Brasileira de Educação Ambiental, v. 13, p. 153-169, 2018. doi: 10.34024/revbea.2018.v13.2468.

ANSELMO, Josiane Santana; AIRES, Isabel Cristina S.; LIMA, Renato Abreu. A educação ambiental e o ensino de biologia em uma escola privada no município de Porto Velho-RO.

Semana Educa, v. 1, p.1-9, 2013. Disponível em:

file:///C:/Users/ROQUINHO/Downloads/1113-4051-1-PB.pdf. Acesso em março de 2020.

BONO, José Antonio Maior et al. Cobertura vegetal e perdas de solo por erosão em diversos sistemas de melhoramento de pastagens nativas. Pasturas Tropicales, v. 18, p. 2-8, 1996. Disponível em: https://ainfo.cnptia.embrapa.br/digital/bitstream/item/113297/1/Vol18-rev296-art2.pdf. Acesso em janeiro de 2020.

BRIGHENTI, Josiane; BIAVATTI, Vania Tanira; DE SOUZA, Taciana Rodrigues. Metodologias de ensino-aprendizagem: uma abordagem sob a percepção dos alunos. Revista Gestão Universitária na América Latina - GUAL, v. 8, n. 3, p. 281-304, 2015. doi: 10.5007/1983-4535.2015v8n3p281.

CARVALHO, Isabel Cristina de Moura. Em direção ao mundo da vida: interdisciplinaridade e educação ambiental. Brasília: IPÊ - Instituto de Pesquisas Ecológicas, 1998.

DIAS, Genebaldo Freire. Os quinze anos da Educação Ambiental no Brasil: um depoimento. Em aberto, v. 10, n. 49, p. 3-14, 1991. Disponível em: http://portal.inep.gov.br/documents/186968/485895/Educa\%C3\%A7\%C3\%A3o+ambiental/3 7cbac3e-3bc6-4783-bc30-017a350437b5?version=1.3. Acesso em maio de 2020.

DICKMANN, Ivo; CARNEIRO, Sônia Maria Marchiorato. Paulo Freire e Educação ambiental: contribuições a partir da obra Pedagogia da Autonomia. Revista de Educação Pública, v. 21, n. 45, p. 87-102, 2012. Disponível em: http://periodicoscientificos.ufmt.br/ojs/index.php/educacaopublica/article/view/334/302. Acesso em maio de 2020.

FERNANDES, José Artur Barroso. Você vê essa adaptação? A aula de campo em ciências entre o retórico e o empírico. Tese (Doutorado em Educação) - Faculdade de Educação, Universidade de São Paulo, São Paulo, 2007. Disponível em:

https://www.teses.usp.br/teses/disponiveis/48/48134/tde-14062007-165841/pt-br.php. Acesso em janeiro de 2020.

FERREIRA, André Luis de Souza; PASA, M aria Corette. Aula de campo como metodologia de ensino em ecologia de florestas, chapada dos Guimarães-MT, BRASIL. Biodiversidade, v. 14, p. 49-62, 2015. Disponível em: 
http://periodicoscientificos.ufmt.br/ojs/index.php/biodiversidade/article/view/2251/1620. Acesso em janeiro de 2020.

FRENEDOZO, Rita de Cássia; RIBEIRO, Júlio César; COSTA, Célio Pereira. Atividades de campo no ensino de ciências: uma abordagem de educação ambiental no ensino fundamental na cidade de Bertioga, estado de São Paulo. Anais do VI Encontro Nacional de Pesquisa em Educação e Ciências, Florianópolis/SC, 2007. Disponível em: http://www.nutes.ufrj.br/abrapec/vienpec/CR2/p376.pdf. Acesso em janeiro de 2020.

GUIMARÃES, Mauro. Educação ambiental: no consenso um embate? Campinas: Papirus, 2000 .

HAMMER, Øyvind; HARPER, David A. T.; RYAN, Paul D. PAST: Paleontological Statistics Software Package for Education and Data Analysis. Palaeo Electronica, v.4, p.1-9. 2001.Disponível em: https://palaeo-electronica.org/2001_1/past/past.pdf. Acesso em novembro de 2018.

HIGUCHI, Maria Inês Gasparetto; AZEVEDO, Genoveva Chagas. Educação como processo na construção da cidadania ambiental. Revista Brasileira de Educação Ambiental, v. 1, p. 63-70, 2004. doi: 10.34024/revbea.2004.v1.1859.

JACOBI, Pedro. Educação e meio ambiente-transformando as práticas. Revista Brasileira de Educação Ambiental, Brasília, v. 1, p. 28-35, 2004. doi: 10.34024/revbea.2004.v1.1859.

KLINK, Carlos A.; MACHADO, Ricardo B. Conservation of the Brazilian Cerrado. Conservation Biology, v. 19, p. 707-713, 2005. doi: 10.1111/j.1523-1739.2005.00702.x.

MACHADO, Ricardo B.; NETO, Mário B. Ramos; PEREIRA, Paulo Gustavo P.; CALDAS, Eduardo F.; GONÇALVES, Demerval A.; SANTOS, Nazareno S.; TABOR, Karyn; STEININGER, Marc. Estimativas de perda da área do Cerrado brasileiro. Conservação Internacional, Brasília, DF, 2004. Disponível em:

http://cmbbc.cpac.embrapa.br/RelatDesmatamCerrado\%20CIBrasi1\%20JUL2004.pdf. Acesso em novembro de 2018.

MADEIRA, Miguel Carlos. Situações em que a aula expositiva ganha eficácia. XII Congresso Nacional de Educação, Araçatuba/SP, 2015. Disponível em:

https://educere.bruc.com.br/arquivo/pdf2015/21752_10083.pdf. Acesso em fevereiro de 2020.

MARCATTO, Celso. Educação Ambiental: Conceitos e Princípios, $1^{\text {a }}$ edição setembro, Belo Horizonte: FEAM, 2002. Disponível em:

http://www.feam.br/images/stories/arquivos/Educacao_Ambiental_Conceitos_Principios.pdf. Acesso em novembro de 2018.

MITTERMEIER, Russell. A.; TURNER, Will R.; LARSEN, Frank Wugt; BROOKS, Thomas M.; GASCON, Claude. Global biodiversity conservation: the critical role of hotspots. In: ZACHOS, Frank E.; HABEL, Jan Christian. Biodiversity hotspot. London: Springer Publishers, 2011. p. 3-22. Disponível em: https://www.researchgate.net/publication/225989074_Global_Biodiversity_Conservation_The _Critical_Role_of_Hotspots. Acesso em agosto de 2020. 
MORAES, Sandra Regina; ADACHESKI, Desyrre Raphaela; CRUZ, Lutécia Hiera; ROCHA, José Roberto Caetano. Investigação da eficácia de aulas teóricas e práticas no processo ensino-aprendizagem de estudantes do $5^{\circ}$ ano. Ensino \& Pesquisa, v. 14, p. 188213, 2016. Disponível em:

http://periodicos.unespar.edu.br/index.php/ensinoepesquisa/article/view/1197/629. Acesso em dezembro de 2019.

MOTOKANE, Marcelo Tadeu; TRIVELATO, Silvia L.F. Reflexões sobre o ensino de ecologia no ensino médio. Anais II Encontro Nacional de Pesquisa em Educação em Ciências, 1999. Disponível em: http://www.abrapecnet.org.br/enpec/iienpec/trabalhos/G32.pdf. Acesso em janeiro de 2019.

NASCIMENTO, Maria Vitória Élida; ALMEIDA, Elinei Araújo. Importância da realização de trilhas participativas para o conhecimento e conservação da diversidade biológica: uma análise da percepção ambiental. Revista Eletrônica do Mestrado em Educação Ambiental, v. 23 , p. 358-368, 2009. doi: 10.14295/remea.v23i0.4565.

NOGUEIRA, Bárbara Gabriele de Souza; GONÇALVES, Guilherme Machado; MENEZES, Raquel Vizzotto; RODRIGUES, Reginaldo. Educação Ambiental: a relação entre as aulas de Campo e o conteúdo formal da Biologia. X Congresso Nacional de Educação (EDUCERE)/ I Seminário Internacional de Representações Sociais, Subjetividade e Educação (SIRSSE), Curitiba/PR, 2011. Disponível em:

https://educere.bruc.com.br/cd2011/pdf/4441_3410.pdf. Acesso em novembro de 2018.

QGIS DEVELOPMENT TEAM. QGIS Geographic Information System. Open Source Geospatial Foundation, 2020. Disponível em: http://qgis.org. Acesso em agosto de 2020.

RATTER, James Alexander; RIBEIRO, José Felipe; BRIDGEWATER, Samuel. The Brazilian Cerrado vegetation and threats to its biodiversity. Annals of Botany, v. 80, p. 223230, 1997. doi: 10.1006/anbo.1997.0469.

ROCHA, Artur Batista de Oliveira. Trabalhando com educação ambiental no ensino de Biologia. UNAR, v. 4, p. 38-46, 2010. Disponível em:

http://revistaunar.com.br/cientifica/documentos/vol4_n1_2010/5_trabalhando_com_educacao _ambiental.pdf. Acesso em novembro de 2018.

RODRIGUES, José Jorge Vale; STROHSCHOEN, Andreia Aparecida Guimaraes; MARCHI, Miriam Inês. Potencialidades das saídas a campo: reflexões a respeito do ensino de física e meio ambiente. Revista Ciência em Extensão, v. 13, p.44-59, 2017. Disponível em: https://ojs.unesp.br/index.php/revista_proex/article/view/1521/1373. Acesso em novembro de 2018.

SANTOS, Bianca Guimarães Severo; ROYER, Marcia Regina. O desenvolvimento do pensamento crítico sobre educação ambiental e meio ambiente: concepção dos alunos do ensino médio do município de UNIFLOR - PR. Revista Prática Docente, v. 5, p. 234-248, 2020. https://doi.org/10.23926/RPD.2526-2149.2020.v5.n1.p234-248.id578.

SENICIATO, Tatiana; CAVASSAN, Osmar. Aulas de campo em ambientes naturais e aprendizagem em ciências: um estudo com alunos do ensino fundamental. Ciência e Educação, v. 10, p. 133-147, 2004. doi: 10.1590/S1516-73132004000100010. 
SOARES, Wagner Lopes; PORTO, Marcelo Firpo. Atividade agrícola e externalidade ambiental: uma análise a partir do uso de agrotóxicos no Cerrado brasileiro. Ciência e Saúde Coletiva, v. 12, p. 131-143, 2007. doi: 10.1590/S1413-81232007000100016.

VIVEIRO, Alessandra Aparecida; DINIZ, Renato Eugênio da Silva. Atividades de campo no ensino das ciências e na educação ambiental: refletindo sobre as potencialidades desta estratégia na prática escolar. Ciência em Tela, v. 2, p. 9-13, 2009. Disponível em: http://www.cienciaemtela.nutes.ufrj.br/artigos/0109viveiro.pdf. Acesso em novembro de 2018.

ZACARIAS, Rachel. Consumo, lixo e educação ambiental: uma abordagem crítica. Juiz de Fora: FEME, 2000.

Recebido em: 6 de junho de 2020.

Aprovado em: 30 de agosto de 2020. 